\title{
Prognostic significance of the methylation of Wnt pathway antagonists-CXXC4,DACT2, and the inhibitors of sonic hedgehog signaling-ZIC1, ZIC4, and HHIP in head and neck squamous cell carcinomas
}

\author{
Jarosław Paluszczak ${ }^{1}$ (D) Dorota Wiśniewska ${ }^{1} \cdot$ Magdalena Kostrzewska-Poczekaj $^{2}$. \\ Katarzyna Kiwerska ${ }^{2}$ - Reidar Grénman ${ }^{3}$ - Daniela Mielcarek-Kuchta ${ }^{4}$. \\ Malgorzata Jarmuż-Szymczak ${ }^{2}$
}

Received: 2 June 2016 / Accepted: 16 August 2016/Published online: 23 August 2016

(C) The Author(s) 2016. This article is published with open access at Springerlink.com

\begin{abstract}
Objectives Aberrations in Wnt and Shh signaling pathways are related to the pathogenesis of head and neck carcinomas, and their activation frequently results from epigenetic alterations. This study aimed to assess the frequency of methylation of negative regulators of Wnt signaling: $C X X C 4, D A C T 2$, HDPRl, and FBXW11 and Shh signaling: HHIP, PTCH1, $S U F U$, ZICl, and ZIC4 and correlate it with clinicopathological features in this group of patients.

Materials and methods Methylation-specific PCR was used to detect gene promoter methylation, and real-time PCR was used to assess gene expression level.

Results The analysis of the occurrence of gene promoter methylation in head and neck carcinoma cell lines indicated that CXXC4, DACT2, HHIP, ZIC1, and ZIC4 are methylated in these tumors. These genes were further analyzed in tumor sections from oral and laryngeal cancer patients. Gene methylation rate was higher in laryngeal tumors. The methylation index in tumor samples correlated with the overall survival in
\end{abstract}

Jarosław Paluszczak

paluszcz@ump.edu.pl

1 Department of Pharmaceutical Biochemistry, Poznan University of Medical Sciences, ul. Święcickiego 4, 60-781 Poznań, Poland

2 Department of Cancer Genetics, Institute of Human Genetics, Polish Academy of Sciences, Poznań, Poland

3 Department of Otorhinolaryngology, Head and Neck Surgery and Department of Medical Biochemistry, Turku University Central Hospital and Turku University, Turku, Finland

4 Department of Otolaryngology and Laryngological Oncology, Poznan University of Medical Sciences, Poznań, Poland a subgroup of oral cancer patients who died of the disease. Moreover, ZIC4 methylation correlated with lymph node involvement in oral cancer patients.

Conclusions Our findings corroborate that the activation of Wnt signaling in head and neck squamous cell carcinoma (HNSCC) is related to epigenetic silencing of its negative regulators. Moreover, the results indicate that the same mechanism of activation may operate in the case of Shh signaling. Clinical relevance The methylation of ZIC4 may be considered a new prognostic marker in oral cavity and oropharyngeal tumors. Further investigations should determine the diagnostic significance of methylation of ZIC4, HHIP, and DACT2 in head and neck carcinomas.

Keywords Head and neck cancer · DNA methylation · Shh pathway $\cdot$ Wnt pathway $\cdot$ ZIC4

\author{
Abbreviations \\ HNSCC Head and neck squamous cell carcinoma \\ LSCC Laryngeal squamous cell carcinoma \\ OSCC Oral squamous cell carcinoma
}

\section{Introduction}

Head and neck cancers consist approximately $6 \%$ of all cancer cases in Poland with nearly six thousand new cases annually $[1,2]$. Despite recent advancements in oncology, the fiveyear survival rates in head and neck cancers have remained unchanged and are estimated overall around 50-60\%. The prognosis is much worse in the case of patients suffering from more advanced (regional and distant) tumors. New therapeutic 
strategies and diagnostic markers are necessary for the improvement of treatment outcomes. The molecular biology of head and neck squamous cell carcinomas (HNSCC) which are the most prevalent type of head and neck malignancy is increasingly well understood what currently forms the basis for the search of both new biomarkers and novel chemotherapeutic strategies. Among the many molecular aberrations observed in HNSCC, changes in the activity of signaling pathways such as TGF $\beta$, Ras/PI3K/AKT/mTOR, Notch, or NFkB which are responsible for the regulation of cell proliferation, migration, and cell death emerge as important factors associated with both the pathogenesis and progression of the disease [3-5]. Recently, aberrations in the function of sonic hedgehog (Shh) and canonical Wnt pathways have been also implicated in the development of HNSCC.

Canonical Wnt signaling regulates the nuclear translocation of $\beta$-catenin. In unstimulated cells, $\beta$-catenin is sequestered in the cytoplasm by an inhibitory complex which consists of axin, APC, casein kinase and glycogen synthase kinase-GSK $3 \beta$. In these conditions, $\beta$-catenin undergoes phosphorylation and is targeted for proteasomal degradation. The binding of Wnt ligands to membrane frizzled/LRP receptors causes the destabilization of the inhibitory complex via activation of disheveled and leads to the release of $\beta$-catenin which enters the nucleus and binds to TCF/LEF transcription factors. This stimulates the transcription of various genes responsible for cell cycle regulation and cell migration including CCND1 (encoding cyclin D1), survivin, MMP-7 (encoding matrix metalloproteinase 7), and $c-M y c$ [6]. The precise regulation of the pathway is also secured by the activity of a group of proteins which antagonize the progression of the pathway in a stage-specific manner. The activation of canonical Wnt pathway is detected already in precancerous lesions [7, 8], and its dysregulation may increase with tumor progression attributing to enhanced cancer cell migration and thus worse prognosis [9-11]. The activation of Wnt signaling in HNSCC is rarely the result of genetic mutations but usually occurs due to the hypermethylation of genes encoding the negative regulators of the pathway [12-15]. The methylation of Wnt pathway antagonists such as SFRP1-5,DKK1-3, WIF1, DACH1, and $P P P 2 R 2 B$ has been frequently observed, and it was associated with worse prognosis [15-18]. The biological importance of Wnt dysregulation for the development of HNSCC is corroborated by the fact that the growth of tongue cancer cells is inhibited by the silencing of CTNNB1 gene which encodes $\beta$-catenin [19].

Sonic hedgehog is another signaling pathway active in embryonal and somatic stem cells which undergoes activation in human cancers [20] and may have crosstalk with Wnt signaling. The binding of Shh ligand to patched (PTCH1) protein relieves the inhibition of smoothened (SMO) which is then able to relieve the sequestration of a Glil transcription factor by a cytoplasmic complex which includes SUFU (suppressor of fused homolog).
This subsequently induces Gli1 translocation to the nucleus where it stimulates the expression of genes related to cell proliferation and cell cycle regulation. Evidence for the implication of Shh pathway dysregulation in the pathogenesis of HNSCC has only recently started to accumulate [21-24]. Importantly, Shh activation was associated with disease progression and worse prognosis in oral squamous cell carcinoma (OSCC) [25]. Based on these findings, Shh signaling has been indicated as a new therapeutic target in this tumor type [26]. Indeed, treatment of HNSCC cells with Shh inhibitor cyclopamine suppressed cell growth and enhanced the cytotoxic effects of cisplatin and docetaxel [27]. However, the molecular mechanisms leading to the activation of Shh in HNSCC have not been well studied although it is suggested that this may occur due to epigenetic changes [28].

The association between the dysregulation of Wnt and Shh pathways and the pathogenesis of HNSCC implicates the possibility of therapeutic targeting HNSCC by modulating the activity of these pathways. This however requires a thorough understanding of the molecular mechanisms which lead to pathway activation, and epigenetic mechanisms have emerged as the possibly most important factor which attributes to this phenomenon. Relatively, much is known about the effect of epigenetic silencing of several negative regulators of $\mathrm{Wnt}$ pathway on its activation in HNSCC although the studies have focused only on few regulatory genes so far. On the other hand, the contribution of epigenetic mechanisms to Shh activation in HNSCC has not been well studied and requires exploration. Most importantly, epigenetic silencing of negative regulators of Wnt and Shh pathways may have diagnostic significance. Thus, the aim of the present study was to assess the frequency of methylation of the selected negative regulators of Wnt signaling: CXXC4, DACT2, HDPR1 (DACT1), and FBXW11 and Shh signaling: HHIP, PTCH1, SUFU, $Z I C 1$, and ZIC4 which were either rarely or never under study in head and neck cancers previously and correlate it with clinicopathological features in a group of HNSCC patients.

\section{Materials and methods}

\section{Cell lines}

Thirty-six cell lines which were derived from squamous cell carcinomas of the head and neck region at the University of Turku, Finland [29] were analyzed. The characteristics of the patients whose surgically removed tumor sections were used for the establishment of the respective cell lines are presented in Table 1.

\section{Patients}

The study group consisted of 42 patients with primary oral/oropharyngeal squamous cell carcinoma (localized 
Table 1 Characteristics of the patients and the derived cell lines

\begin{tabular}{|c|c|c|c|c|c|c|c|}
\hline $\begin{array}{l}\text { Name of } \\
\text { cell line }\end{array}$ & Sex & Age & $\begin{array}{l}\text { Primary tumor } \\
\text { location }\end{array}$ & $\begin{array}{l}\text { TNM } \\
\text { staging }\end{array}$ & Specimen site & $\begin{array}{l}\text { Type of } \\
\text { lesion }\end{array}$ & $\begin{array}{l}\text { Histological } \\
\text { grade }\end{array}$ \\
\hline UT-SCC-4 & $\mathrm{F}$ & 43 & $\begin{array}{l}\text { Hypopharynx/ } \\
\text { supraglottic larynx }\end{array}$ & $\mathrm{T}_{3} \mathrm{~N}_{0} \mathrm{M}_{0}$ & Neck & met & G2 \\
\hline UT-SCC-6A & $\mathrm{F}$ & 51 & Supraglottic larynx & $\mathrm{T}_{2} \mathrm{~N}_{1} \mathrm{M}_{0}$ & Larynx & rec & G1 \\
\hline UT-SCC-6B & $\mathrm{F}$ & 51 & Supraglottic larynx & $\mathrm{T}_{2} \mathrm{~N}_{1} \mathrm{M}_{0}$ & Neck & met & G1 \\
\hline UT-SCC-7 & $\mathrm{M}$ & 67 & Skin (temporal region) & $\mathrm{T}_{1} \mathrm{~N}_{0} \mathrm{M}_{0}$ & Neck & met & G2 \\
\hline UT-SCC-8 & $\mathrm{M}$ & 42 & Supraglottic larynx & $\mathrm{T}_{2} \mathrm{~N}_{0} \mathrm{M}_{0}$ & Larynx & pri & G1 \\
\hline UT-SCC-10 & $\mathrm{M}$ & 62 & Tongue scc & $\mathrm{T}_{1} \mathrm{~N}_{0} \mathrm{M}_{0}$ & Tongue & pri & $\mathrm{G} 2$ \\
\hline $\begin{array}{l}\text { UT-SCC- } \\
16 \mathrm{~A}\end{array}$ & $\mathrm{~F}$ & 77 & Tongue scc & $\mathrm{T}_{3} \mathrm{~N}_{0} \mathrm{M}_{0}$ & Tongue & pri & G3 \\
\hline $\begin{array}{c}\text { UT-SCC- } \\
16 \mathrm{~B}\end{array}$ & F & 77 & Tongue scc & $\mathrm{T}_{3} \mathrm{~N}_{0} \mathrm{M}_{0}$ & Neck & met & G3 \\
\hline UT-SCC-17 & $\mathrm{M}$ & 65 & Supraglottic larynx & $\mathrm{T}_{2} \mathrm{~N}_{0} \mathrm{M}_{0}$ & Sternum & met & G3 \\
\hline $\begin{array}{l}\text { UT-SCC- } \\
\text { 19A }\end{array}$ & M & 44 & Glottic larynx & $\mathrm{T}_{4} \mathrm{~N}_{0} \mathrm{M}_{0}$ & Larynx & pri & G2 \\
\hline $\begin{array}{l}\text { UT-SCC- } \\
\text { 19B }\end{array}$ & M & 44 & Glottic larynx & $\mathrm{T}_{4} \mathrm{~N}_{0} \mathrm{M}_{0}$ & Larynx & pri (per) & G2 \\
\hline $\begin{array}{l}\text { UT-SCC- } \\
20 \mathrm{~A}\end{array}$ & $\mathrm{~F}$ & 58 & Floor of mouth & $\mathrm{T}_{1} \mathrm{~N}_{0} \mathrm{M}_{0}$ & Floor of mouth & pri (per) & G2 \\
\hline $\begin{array}{l}\text { UT-SCC- } \\
\text { 20B }\end{array}$ & $\mathrm{F}$ & 58 & Floor of mouth & & Floor of mouth & resid & G2 \\
\hline UT-SCC-22 & $\mathrm{M}$ & 79 & Glottic larynx & $\mathrm{T}_{1} \mathrm{~N}_{0} \mathrm{M}_{0}$ & Larynx & $\mathrm{rec}$ & G2 \\
\hline UT-SCC-23 & M & 66 & Transglottic larynx & $\mathrm{T}_{3} \mathrm{~N}_{0} \mathrm{M}_{0}$ & Larynx & pri (per) & G1 \\
\hline $\begin{array}{l}\text { UT-SCC- } \\
24 \mathrm{~A}\end{array}$ & M & 41 & Tongue scc & $\mathrm{T}_{2} \mathrm{~N}_{0} \mathrm{M}_{0}$ & Tongue & pri & G2 \\
\hline $\begin{array}{l}\text { UT-SCC- } \\
24 \mathrm{~B}\end{array}$ & M & 41 & Tongue scc & & Neck & met (per) & G2 \\
\hline UT-SCC-29 & $\mathrm{M}$ & 82 & Glottic larynx & $\mathrm{T}_{2} \mathrm{~N}_{0} \mathrm{M}_{0}$ & Larynx & pri & G1 \\
\hline UT-SCC-34 & M & 63 & Supraglottic larynx & $\mathrm{T}_{4} \mathrm{~N}_{0} \mathrm{M}_{0}$ & $\begin{array}{l}\text { Supraglottic } \\
\text { larynx }\end{array}$ & pri & G1 \\
\hline UT-SCC-35 & $\mathrm{M}$ & 50 & Glottic larynx & $\mathrm{T}_{2} \mathrm{~N}_{0} \mathrm{M}_{0}$ & Larynx & resid & $\mathrm{G} 2$ \\
\hline UT-SCC-36 & M & 46 & Floor of mouth & $\mathrm{T}_{4} \mathrm{~N}_{1} \mathrm{M}_{0}$ & Floor of mouth & pri & G3 \\
\hline UT-SCC-38 & $\mathrm{M}$ & 66 & Glottic larynx & $\mathrm{T}_{2} \mathrm{~N}_{0} \mathrm{M}_{0}$ & Larynx & pri & $\mathrm{G} 2$ \\
\hline UT-SCC-45 & $\mathrm{M}$ & 76 & Floor of mouth & $\mathrm{T}_{3} \mathrm{~N}_{1} \mathrm{M}_{0}$ & Floor of mouth & pri & G3 \\
\hline UT-SCC-47 & M & 78 & Floor of mouth & $\mathrm{T}_{2} \mathrm{~N}_{0} \mathrm{M}_{0}$ & Floor of mouth & pri & G3 \\
\hline UT-SCC-56 & $\mathrm{M}$ & 62 & Floor of mouth & $\mathrm{T}_{\mathrm{x}} \mathrm{N}_{2} \mathrm{M}_{0}$ & Floor of mouth & rec & $\mathrm{G} 2-\mathrm{G} 3$ \\
\hline UT-SCC-58 & M & 63 & Transglottic larynx & $\mathrm{T}_{4} \mathrm{~N}_{1} \mathrm{M}_{0}$ & Neck & met (skin) & G1 \\
\hline UT-SCC-85 & M & 55 & Tongue scc & $\mathrm{T}_{3} \mathrm{~N}_{0} \mathrm{M}_{0}$ & $\begin{array}{l}\text { Tongue floor of } \\
\text { mouth }\end{array}$ & rec & G2 \\
\hline UT-SCC-90 & $\mathrm{M}$ & 35 & Tongue scc & $\mathrm{T}_{1} \mathrm{~N}_{0} \mathrm{M}_{0}$ & Floor of mouth & $\mathrm{rec} / \mathrm{met}$ & G2 \\
\hline UT-SCC-100 & M & 70 & Gingival scc & $\mathrm{rT}_{3}$ & $\begin{array}{l}\text { Mucosae } \\
\text { bucchae }\end{array}$ & rec & G3 \\
\hline UT-SCC-103 & M & 51 & Glottic larynx & $\mathrm{T}_{3} \mathrm{~N}_{0} \mathrm{M}_{0}$ & Larynx & pri (per) & G2 \\
\hline UT-SCC-104 & $\mathrm{M}$ & 80 & Supraglottic larynx & $\mathrm{T}_{1} \mathrm{~N}_{2 \mathrm{~A}} \mathrm{M}_{0}$ & Neck & met & $\mathrm{G} 2$ \\
\hline $\begin{array}{c}\text { UT-SCC- } \\
\text { 106A }\end{array}$ & M & 59 & Glottic larynx & $\mathrm{T}_{1 \mathrm{~A}} \mathrm{~N}_{0} \mathrm{M}_{0}$ & Larynx & pri & G2 \\
\hline $\begin{array}{c}\text { UT-SCC- } \\
\text { 106B }\end{array}$ & M & 59 & Glottic larynx & $\mathrm{rT}_{3} \mathrm{~N}_{0} \mathrm{M}_{0}$ & Larynx & rec & G3 \\
\hline UT-SCC-107 & M & 46 & Supraglottic larynx & $\mathrm{T}_{4} \mathrm{~N}_{2 \mathrm{C}} \mathrm{M}_{0}$ & Larynx & pri & G2 \\
\hline UT-SCC-108 & $\mathrm{M}$ & 68 & Supraglottic larynx & $\mathrm{T}_{2} \mathrm{~N}_{0} \mathrm{M}_{0}$ & Larynx & pri & G3 \\
\hline UT-SCC-116 & M & 60 & Supraglottic larynx & $\mathrm{T}_{4} \mathrm{~N}_{1} \mathrm{M}_{0}$ & Larynx & pri & G2 \\
\hline
\end{tabular}

$F$ female, $M$ male, $s c c$ squamous cell carcinoma, pri primary, per persistent, rec recurrent, met metastasis, resid residual mostly in tongue or tonsils) and 30 patients with primary laryngeal squamous cell carcinoma (LSCC) who were primarily treated surgically at the Department of Otolaryngology and Laryngological Oncology, Poznan University of Medical Sciences. In the case of oral cancer patients, a tumor section along with a fragment of macroscopically normal surgical margin was obtained from each patient for analysis. Only tumor sections which contained at least $80 \%$ of cancer cells were qualified for further investigation. Patient follow-up observation usually covered at least 3 years post-operation.
Eighteen OSCC and 12 LSCC patients died of the disease during follow-up. The study was approved by the local ethics committee at Poznan University of Medical Sciences. The clinical characteristics of the study group are presented in Table 2.

\section{Methylation-specific PCR}

DNA samples from the early passage cell lines and from a clinical material were prepared using standard phenol/ 
Table 2 Clinical characteristics of patients in the study group

\begin{tabular}{|c|c|c|c|}
\hline & & OSCC & LSCC \\
\hline \multirow[t]{2}{*}{ Age } & Range & $28-84$ & $39-79$ \\
\hline & Mean & 57 & 57 \\
\hline \multirow[t]{2}{*}{ Sex } & Female & 4 & 2 \\
\hline & Male & 38 & 28 \\
\hline \multirow[t]{9}{*}{ TNM staging } & $\mathrm{T} 1$ & 4 & 0 \\
\hline & $\mathrm{T} 2$ & 23 & 2 \\
\hline & $\mathrm{T} 3$ & 8 & 17 \\
\hline & $\mathrm{T} 4$ & 7 & 11 \\
\hline & No & 20 & 21 \\
\hline & N1 & 13 & 4 \\
\hline & $\mathrm{N} 2$ & 7 & 5 \\
\hline & N3 & 2 & 0 \\
\hline & M0 & 42 & 30 \\
\hline \multirow[t]{3}{*}{ G histological stage } & G1 & 9 & 8 \\
\hline & G2 & 26 & 21 \\
\hline & G3 & 7 & 1 \\
\hline \multirow[t]{3}{*}{ Overall survival time (months) } & Range & $0-72$ & $4-93$ \\
\hline & Mean & 30 & 54 \\
\hline & Tumor-related death & 18 & 12 \\
\hline \multirow[t]{3}{*}{ Other } & Recurrence & 6 & 11 \\
\hline & Metastasis & 1 & 1 \\
\hline & Second primary tumor & 2 & 0 \\
\hline
\end{tabular}

chloroform extraction protocol. Methylation-specific PCR (MSP) was used for the analysis of gene promoter methylation [30]. Prior to amplification, all the DNA samples underwent bisulfite conversion using an EZ DNA methylation Kit (ZymoResearch, USA) according to manufacturer's protocol. Primer sequences for the analysis of $C X X C 4, F B X W 11$, SUFU, ZICl, and ZIC4 were designed using the MethPrimer online software [31] and are presented in Table 3. Primer sequences used for the analysis of DACT2, HDPR1, HHIP, and PTCH1 were previously described [32-35]. All the primers were obtained from the oligonucleotide synthesis facility at the Institute of Biochemistry and Biophysics, Polish Academy of Sciences. DNA derived from white blood cells of healthy donors and fully methylated human genomic DNA (Thermo Scientific, USA) were used as negative and positive MSP controls, respectively. Moreover, samples of genomic DNA extracted from early passage primary culture of human oral keratinocytes and human tracheal epithelial cells (ScienCell Research Laboratories, USA) were used as normal controls for comparison. PCR reactions were performed in a T100 thermal cycler (Bio-Rad Laboratories, USA) using HOT FIREPol Polymerase (Solis BioDyne, Estonia). The amplification protocol was as follows: initial enzyme activation for 15 min at $95^{\circ} \mathrm{C}$ followed by 40 cycles of $95^{\circ} \mathrm{C}$ for $30 \mathrm{~s}, X^{\circ} \mathrm{C}$ for $30 \mathrm{~s}$ and $72{ }^{\circ} \mathrm{C}$ for $30 \mathrm{~s}$, and the final elongation at $72{ }^{\circ} \mathrm{C}$ for $5 \mathrm{~min}$, where $X$ stands for the appropriate annealing temperature as described in Table 3. PCR products were resolved on $2 \%$ agarose gels in the presence of the Midori Green DNA stain (Nippon Genetics, Japan) and subsequently visualized under UV light illumination. The resulting electrophoregrams were interpreted as previously [17]. In the case of the cell lines, the presence of the band only in the reaction with the starters specific for the unmethylated sequence was treated as lack of gene methylation (U), whereas the presence of the band only in the reaction with the starters specific for the methylated sequence was treated as full gene methylation (M). Partial methylation $(\mathrm{M} / \mathrm{U})$ was detected when bands were observed in both reactions. Because DNA samples extracted from tumor sections cannot be treated as derived from a rather homogenous population of cancer cells (as in the case of cell lines), thus a simplified interpretation was used. Gene methylation (M) was detected in each case when the band in the reaction with the starters specific for the methylated sequence was present. Lack of gene methylation (U) was detected in each case when the band in the reaction with the starters specific for the methylated sequence was missing and only the band in the reaction with the starters specific for the unmethylated sequence was present.

\section{Quantitative PCR}

Standard phenol/guanidine thiocyanate extraction protocol served for the preparation of total RNA samples from early passage cell lines. An RNA sample isolated from first passage primary oral keratinocytes (ScienCell Research Laboratories, USA) was used as a calibrator in gene expression quantification. All RNA samples were reverse transcribed using the RevertAid First Strand cDNA Synthesis Kit (Thermo Scientific) according to manufacturer's protocol. Primer sequences for the analysis of the transcript level of $C X X C 4$, $D A C T 2$, and HHIP were designed using the Beacon Designer software and further BLAST searched to minimize non-specific binding. Each primer pair covered a region spanning two distinct exons. The sequences are listed in Table 4. Quantitative real-time PCR reactions were performed in a Chromo4 thermal cycler (Bio-Rad Laboratories, USA) using the HOT FIREPol Eva Green qPCR Mix (Solis BioDyne, Estonia). The amplification protocol was as follows: initial enzyme activation for $15 \mathrm{~min}$ at $95^{\circ} \mathrm{C}$ followed by $40-45 \mathrm{cy}-$ cles of $95^{\circ} \mathrm{C}$ for $20 \mathrm{~s}, X^{\circ} \mathrm{C}$ for $20 \mathrm{~s}$ and $72^{\circ} \mathrm{C}$ for $40 \mathrm{~s}$, and the final elongation at $72{ }^{\circ} \mathrm{C}$ for $5 \mathrm{~min}$, where $X$ stands for the annealing temperature as described in Table 4. Subsequent melting curve analysis allowed the confirmation of the presence of a single product. Measurements were performed in duplicate, and mean values were normalized using $P B G D$ (porphobilinogen deaminase) as the reference gene. Relative expression level was calculated with the $\Delta \Delta \mathrm{Ct}$ method using 
Table 3 Sequences of the starters used in methylation-specific PCR designed using MethPrimer

\begin{tabular}{|c|c|c|c|}
\hline Gene & Sequence & & $\mathrm{Ta}$ \\
\hline \multirow[t]{4}{*}{$C X X C 4$} & MF & 5' GGAGAGAGAGAGGAGAGATTTTTC 3' & \multirow[t]{2}{*}{$60^{\circ} \mathrm{C}$} \\
\hline & MR & 5' ATAAAAACGCGAATCTATTATCGAT 3' & \\
\hline & UF & 5' AGAGAGAGAGGGAGAGATTTTTTGG 3' & \multirow[t]{2}{*}{$56^{\circ} \mathrm{C}$} \\
\hline & UR & 5' ATAAAAACACAAATCTATTATCAAT 3' & \\
\hline \multirow[t]{4}{*}{$F B X W 11$} & MF & 5' TAGGAAGTTAAGAGAAGTTAGTCGG 3' & \multirow[t]{2}{*}{$59^{\circ} \mathrm{C}$} \\
\hline & MR & 5' CACTAAACGATAAACGTAAAACGTA 3' & \\
\hline & UF & 5' TAGGAAGTTAAGAGAAGTTAGTTGG 3' & \multirow[t]{2}{*}{$59^{\circ} \mathrm{C}$} \\
\hline & UR & 5' CACTAAACAATAAACATAAAACATA 3' & \\
\hline \multirow[t]{4}{*}{$S U F U$} & MF & 5' GTTTCGGGGAGTTTTATTTATC 3' & \multirow[t]{2}{*}{$60^{\circ} \mathrm{C}$} \\
\hline & MR & 5' GAAAACCGAAAAAACAATCG 3' & \\
\hline & UF & 5' GTTTTGGGGAGTTTTATTTATTGA 3' & \multirow[t]{2}{*}{$60^{\circ} \mathrm{C}$} \\
\hline & UR & 5' AAACAAAAACCAAAAAAACAATCA 3' & \\
\hline \multirow[t]{4}{*}{ ZIC1 } & MF & 5' TTTCGTTAAACGTTTATTCGTTTC 3' & \multirow[t]{2}{*}{$62^{\circ} \mathrm{C}$} \\
\hline & MR & 5' CACCTAACCTCCTAAAAACCTACG 3' & \\
\hline & UF & 5' TTTGTTAAATGTTTATTTGATTTTGT 3' & \multirow[t]{2}{*}{$54^{\circ} \mathrm{C}$} \\
\hline & UR & 5' TCACCTAACCTCCTAAAAACCTACA 3' & \\
\hline \multirow[t]{4}{*}{ ZIC4 } & MF & 5' CGGTTCGGTTAGGAAATTTATC 3' & \multirow[t]{2}{*}{$62^{\circ} \mathrm{C}$} \\
\hline & MR & $5^{\prime}$ AACCAAAAAAACGAAAAACGAC 3' & \\
\hline & UF & 5' AGGTGGTTTGGTTAGGAAATTTATT 3' & \multirow[t]{2}{*}{$60^{\circ} \mathrm{C}$} \\
\hline & UR & 5' AAAAACCAAAAAAACAAAAAACAAC $3^{\prime}$ & \\
\hline
\end{tabular}

$M$ methylated, $U$ unmethylated, $F$ forward, $R$ reverse, $T a$ annealing temperature the formula: $\mathrm{RE}=2^{[\mathrm{Ct}(\mathrm{ref})-\mathrm{Ct}(\text { test }) \mathrm{TUMOR}] / 2}[\mathrm{Ct}(\mathrm{ref})-\mathrm{Ct}$ (test) normal keratinocytes]

\section{Statistical analysis}

The association between clinicopathological variables and the occurrence of single gene methylation was analyzed using chi-square or Fisher's exact tests. The association between clinicopathological variables and methylation index was analyzed using the Mann-Whitney $U$ test or Kruskal-Wallis test. The analysis of the association of single gene methylation with overall survival time was performed using the $F$-Cox test. Multiple regression analysis allowed for the establishment of the association between methylation index and overall survival time. All the analyses were performed using the STATISTICA 10 software (StatSoft, Poland), and differences between groups were considered significant when $p \leq 0.05$.

\section{Results}

In the screening stage, the analysis of the occurrence of promoter methylation of the studied genes in DNA samples derived from head and neck squamous cell carcinoma cell lines allowed for the identification of those genes which undergo methylation in these tumors. No methylation was detected for $F B X W 11, P T C H 1$, or $S U F U$ while all the other genes showed relatively low (DACT2) to high (ZIC1) frequency of methylation in the tested cell lines except $H D P R 1$, which was only partly methylated in two cell lines (Table 5). Representative electrophoregrams are shown in Fig. 1. There was no statistically significant difference in the frequency of gene methylation between laryngeal and oral cavity and oropharyngeal carcinoma cell lines. Importantly, none of the genes was methylated in genomic DNA derived from normal oral keratinocytes or tracheal epithelial cells indicating that the methylation of
Table 4 The sequence of starters used in real-time PCR analysis

\begin{tabular}{|c|c|c|c|c|}
\hline \multirow{2}{*}{$\frac{\text { Gene }}{C X X C 4}$} & \multicolumn{2}{|c|}{ Starter sequence } & \multirow{2}{*}{$\begin{array}{l}\text { Amplicon size } \\
105 \mathrm{bp}\end{array}$} & \multirow{2}{*}{$\frac{\text { Annealing T }}{56^{\circ} \mathrm{C}}$} \\
\hline & $\begin{array}{l}\mathrm{F} \\
\mathrm{R}\end{array}$ & $\begin{array}{l}\text { 5' CACCTCСТCСТCСТTCCAC } \\
\text { 5' GCATTATCCTCCAACTGTTACAAC }\end{array}$ & & \\
\hline DACT2 & $\begin{array}{l}\mathrm{F} \\
\mathrm{R}\end{array}$ & $\begin{array}{l}\text { 5' CAGGCTTTTACGAGATGAG } \\
\text { 5' CAGCGAGGGAGAGATGTG }\end{array}$ & 89 bp & $56{ }^{\circ} \mathrm{C}$ \\
\hline HHIP & $\begin{array}{l}\mathrm{F} \\
\mathrm{R}\end{array}$ & $\begin{array}{l}\text { 5' TCCTATACCACCAACCAAGAAC } \\
5^{\prime} \text { TTGTCCTCCCAGATGCTTTC }\end{array}$ & $165 \mathrm{bp}$ & $59^{\circ} \mathrm{C}$ \\
\hline$P B G D$ & $\begin{array}{l}\mathrm{F} \\
\mathrm{R}\end{array}$ & $\begin{array}{l}\text { 5' TCAGATAGCATACAAGAGACC } \\
\text { 5' TGGAATGTTACGAGCAGTG }\end{array}$ & $111 \mathrm{bp}$ & $56^{\circ} \mathrm{C}$ \\
\hline
\end{tabular}

$F$ forward primer, $R$ reverse primer 
Table 5 The frequency of gene promoter methylation in head and neck squamous cell carcinoma cell lines

\begin{tabular}{llllll}
\hline Gene & Methylation status & Frequency (\%) & Gene & Methylation status & Frequency (\%) \\
\hline CXXC4 & $\mathrm{M}$ & 17.2 & HHIP & $\mathrm{M}$ & 27.8 \\
& $\mathrm{M} / \mathrm{U}$ & 22.8 & & $\mathrm{M} / \mathrm{U}$ & 30.5 \\
& $\mathrm{U}$ & 60 & & $\mathrm{U}$ & 41.7 \\
DACT2 & $\mathrm{M}$ & 11.4 & ZIC1 & $\mathrm{M}$ & 88.9 \\
& $\mathrm{M} / \mathrm{U}$ & 14.3 & & $\mathrm{M} / \mathrm{U}$ & 14.3 \\
& $\mathrm{U}$ & 74.3 & $\mathrm{U}$ & 2.8 \\
HDPR1 & $\mathrm{M} / \mathrm{U}$ & 5.7 & $\mathrm{M} 4$ & 22.2 \\
& $\mathrm{U}$ & & $\mathrm{M} / \mathrm{U}$ & 47.2 \\
FBXW11 & $\mathrm{U}$ & 94.3 & & $\mathrm{U}$ & 30.6 \\
PTCH1 & $\mathrm{U}$ & 100 & SUFU & $\mathrm{U}$ & 100 \\
\hline
\end{tabular}

$M$ full gene methylation, $M / U$ partial methylation of gene, $U$ complete lack of gene methylation
CXXC4, DACT2, HHIP, ZIC1, and ZIC4 does not appear in normal epithelial cells. We also wanted to assess whether the methylation of gene promoter regions under analysis correlated with their transcriptional activity. Therefore, we analyzed the expression of those genes which showed differential methylation status among the cell lines (Fig. 2). The expression of these genes in normal human oral keratinocytes (HOK) served as the reference in quantification. The quantitation of the transcript level of CXXC4 and HHIP showed that full gene promoter methylation correlated with decreased level of expression when compared to expression in normal oral keratinocytes. The expression of these genes in cell lines showing only partial methylation or lack of methylation was not suppressed. This indicates that promoter methylation of these genes is associated with loss of their expression in HNSCC cells. Such an association was not observed in the case of $D A C T 2$, where the transcript level was similar irrespective of its methylation status indicating that the methylation of the analyzed promoter region is not the decisive factor in establishing transcription intensity.

Based on the findings that CXXC4, DACT2, HHIP, ZIC1, and ZIC4 are methylated in HNSCC cell lines and that their methylation is not present in normal oral and tracheal epithelium, we further investigated the frequency of methylation of these genes in laryngeal and oral tumor samples and matched surgical margin samples of OSCC patients. Exemplary electrophoregrams are shown in Fig. 3, and the summary of the results is presented in Table 6. The rate of methylation of ZIC1, ZIC4, HHIP, and DACT2 in tumors was very high, while methylation of $C X X C 4$ was low to moderate in OSCC and LSCC. Laryngeal tumors showed generally higher rates of gene methylation than oral cancers. Gene methylation was detected in all LSCC samples. The concurrent methylation of four genes was observed most frequently $(43.7 \%)$ followed by the observation of concurrent methylation of all five genes $(23.3 \%)$. The remaining cases showed the methylation of either three $(20 \%)$ or two $(10 \%)$ genes. Thus, the mean methylation index (MI - number of methylated genes divided by the number of all the tested genes) in LSCC samples was high -0.78 . The occurrence of gene methylation was also highly prevalent among OSCC samples with only three cases showing the lack of methylation of any of the tested genes. Two OSCC cases showed the methylation of all five genes. The concurrent methylation of three genes was observed most frequently $(26.2 \%)$ followed by the concurrent methylation of two or four genes $(23.8 \%)$ or the methylation of a single gene $(14.3 \%)$. The mean methylation index in OSCC samples was 0.56 . The frequency of methylation of the analyzed genes in OSCC surgical margin samples was lower than in the corresponding tumor samples what was reflected by a lower MI value of 0.4 . The analysis of concordance (presence or lack of methylation in both paired samples) or discordance (presence of methylation in only one paired sample) of the results between paired tumor and surgical margin in OSCC patients is presented in Table 7. Most discordant results were associated with the lack of gene methylation in the resection margin.

The presence of gene methylation in tumor samples did not correlate with histological grade or tumor size. However, the presence of ZIC4 methylation in oral tumors significantly correlated with lymph node invasion $(p=0.041)$. The methylation of ZIC4 in tumors did not correlate with the overall survival of patients (Fig. 4) although there was a trend for an association between ZIC4 methylation and shorter survival in OSCC patients $(p=0.09088)$. Moreover, the MI value in oral tumor samples moderately correlated with the overall time of survival in the subgroup of 18 patients who died of the disease $(r=0.46, p=0.05)$. The presence of gene methylation in OSCC surgical margin 


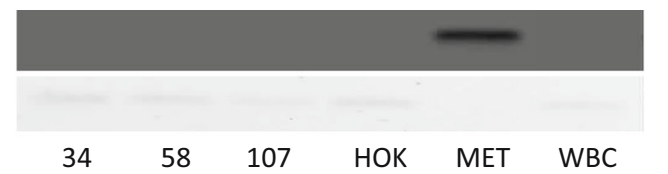

M

CXXC4

34

$\begin{array}{llll}58 & 107 & \text { HOK } & \text { MET }\end{array}$

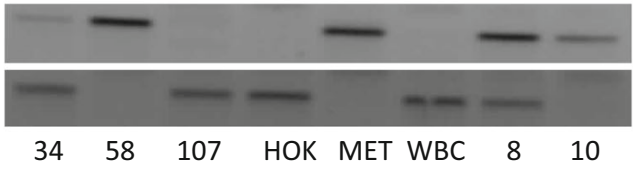

M

DACT2

U

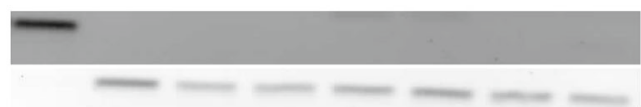

M

FBXW11

$\begin{array}{lllllll}\text { MET WBC } & 8 & 10 & 20 \mathrm{~A} & 20 \mathrm{~B} & 23 & 24 \mathrm{~B}\end{array}$

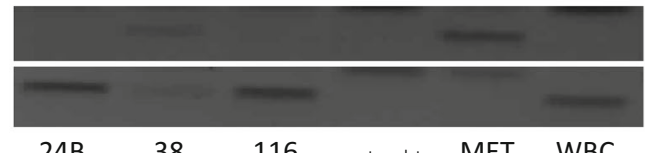

$\mathrm{M}$

HDPR1

24B $38 \quad 116$ notemplate MET WBC

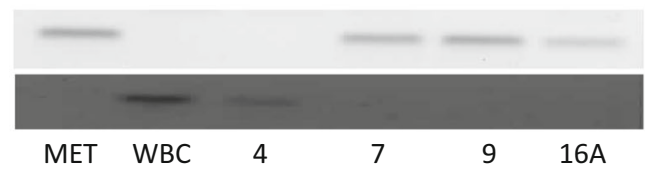

M

HHIP

U

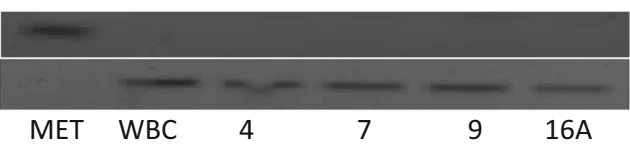

M

U

PTCH1

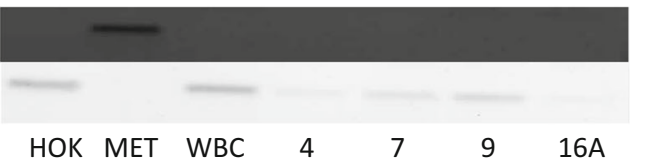

M U

$\begin{array}{llllll}\text { HOK } & \text { MET } & \text { WBC } & 4 & 7 & 9\end{array}$
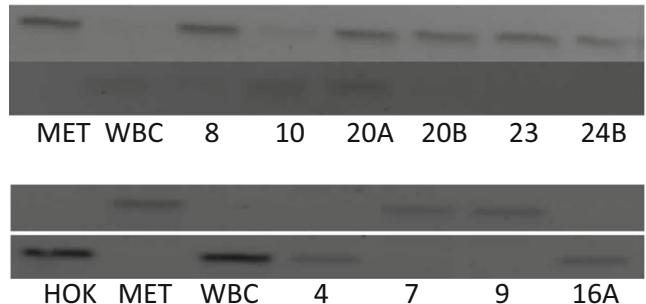

M ZIC1 U

M ZIC4

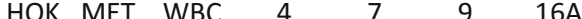

Fig. 1 Representative electrophoregrams for the analysis of $C X X C 4$, DACT2, FBXW11, HDPR1, HHIP, PTCH1, SUFU, ZIC1, and ZIC4 methylation by methylation-specific PCR using starters specific for the methylated sequence $(\mathrm{M})$ and starters specific for the unmethylated sequence (U) in head and neck squamous cell carcinoma cell lines and control DNA samples: $H O K$ DNA isolated from healthy oral keratinocytes, MET completely methylated human DNA, WBC DNA derived from white blood cells of healthy blood donors

did not show any statistically significant correlation with clinicopathological variables. However, the MI value was higher in the case of patients who developed second primary tumors. Although such an association was noted, it has to be considered dubious since there were only two patients in the studied group who
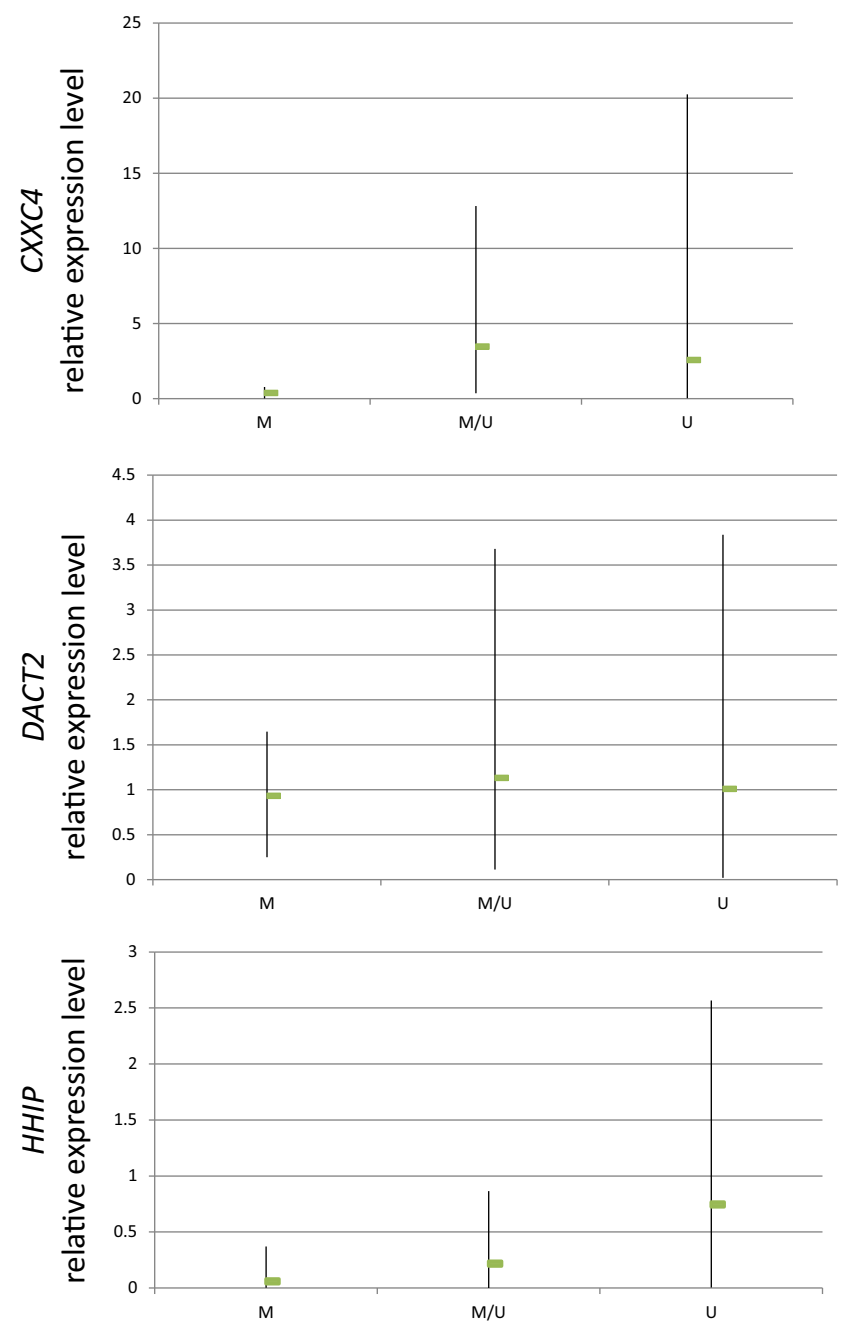

Fig. 2 Relative expression levels of $C X X C 4, D A C T 2$, and HHIP in HNSCC cell lines. The relative level of transcript was calculated as fold difference in relation to the expression in normal human keratinocytes (where expression was adopted as equal 1). The range of relative gene expression among cell lines (minimum and maximum values) and the mean level of relative expression (indicated in the graphs by the arms and the green box, respectively) in cell lines characterized by complete gene methylation $(M)$, partial methylation $(M / U)$, or lack of methylation (U) is shown

developed a second primary tumor during follow-up observation.

\section{Discussion}

Head and neck cancers are preventable tumors which develop mostly due to prolonged exposure to cigarette smoke and alcohol or HPV infection. In many cases, the tumor is diagnosed at a late stage when even aggressive treatment frequently fails to provide positive effects what results in low relapsefree and overall survival rates in patients with regional and distant head and neck carcinoma. Only recently, molecularly targeted therapies with EGFR (epithelial growth factor 

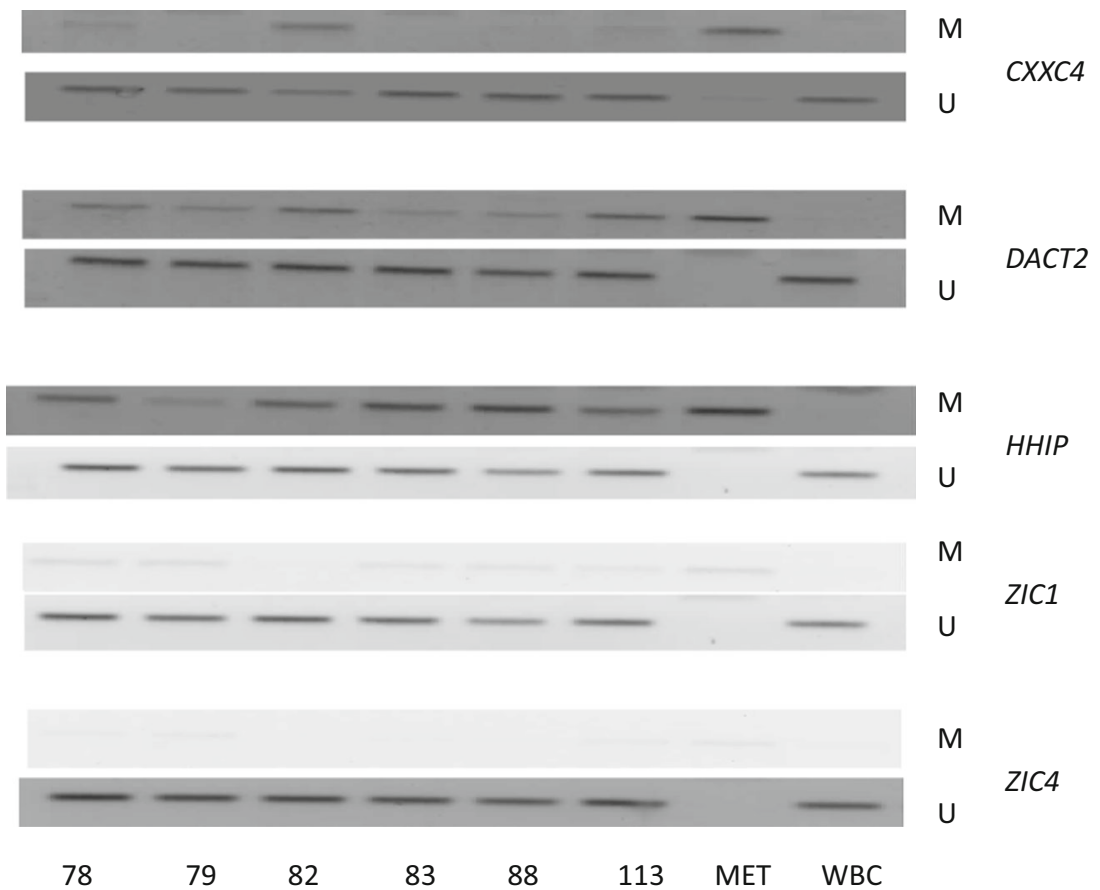

Fig. 3 Representative electrophoregrams for the analysis of $C X X C 4$, $D A C T 2, H H I P, Z I C 1$, and ZIC4 methylation by methylation-specific PCR using starters specific for the methylated sequence (M) and starters specific for the unmethylated sequence $(U)$ in laryngeal tumor samples

(patients no. $78,79,82,83,113$ ) and control DNA samples: MET completely methylated human DNA, WBC DNA derived from white blood cells of healthy blood donors

receptor) inhibitors have been applied with moderate outcomes in HNSCC indicating the need for the search of other therapeutic strategies. The increasing understanding of the molecular landscape in HNSCC points to several signaling pathways as drivers of the oncogenic transformation. Among those pathways, Wnt and Shh signaling seem especially interesting because of the possible association between their deregulation and disease progression. Infrequent mutations of members of these pathways and evidence of epigenetic silencing of their negative regulators stimulate the focus on the epigenetic mechanisms of modulation of the activity of these pathways in HNSCC.

Previous studies have shown that the enhanced transcriptional activity of $\beta$-catenin which is a marker of the activated canonical Wnt signaling is causally related to increased cell proliferation, migration, and epithelial-to-mesenchymal transition in HNSCC $[9,10]$. Thus, the inhibition of $\beta$-catenin resulted in diminished cell growth and motility [19]. The hypermethylation of such negative regulators of Wnt pathway as SFRP1-5, DKK1-3, WIF1, DACH1, and PPP2R2B may significantly contribute to pathway activation and was frequently observed in HNSCC [15-18]. Moreover, both the increased expression of pathway components and the methylation of several antagonists correlated with worse prognosis. Based on these previous findings that the methylation of Wnt antagonists may have diagnostic significance, we decided to analyze the methylation of other genes $(C X X C 4, D A C T 2$, HDPR1, FBXW11) which were not studied in this context in HNSCC. Wnt signaling is antagonized by DACT2 and HDPR1 proteins due to their ability to bind Disheveled and thus prevent the destabilization of the $\beta$-catenin inhibitory complex. The methylation of DACT2 was previously reported in lung and also in gastric and thyroid cancers where it correlated with tumor differentiation and invasion [32, 36, 37]. On the other hand, HDPR1 (DACT1) was downregulated by DNA methylation in breast or hepatocellular carcinoma [33, 38] and its downregulation was associated with poor prognosis in gastric and non-small cell lung cancers [39, 40].
Table 6 The frequency of gene promoter methylation in tumor and resection margin of HNSCC patients

\begin{tabular}{llllcc}
\hline & CXXC4 $(\%)$ & DACT2 $(\%)$ & HHIP $(\%)$ & ZIC1 (\%) & ZIC4 (\%) \\
\hline LSCC & 36.6 & 96.7 & 90 & 86.7 & 78.6 \\
OSCC & 10 & 53 & 62.5 & 100 & 73.2 \\
OSCC margin & 5.9 & 39.4 & 40 & 90 & 55.5 \\
\hline
\end{tabular}


Table 7 The concordance of gene promoter methylation in tumor and resection margin of OSCC patients

\begin{tabular}{llllll}
\hline & CXXC4 (\%) & DACT2 (\%) & HHIP $(\%)$ & ZIC1 (\%) & ZIC4 (\%) \\
\hline $\mathrm{T}+\mathrm{R}+$ & 0 & 31 & 23.7 & 89.5 & 51.4 \\
$\mathrm{~T}+\mathrm{R}-$ & 5.9 & 17.2 & 36.8 & 10.5 & 22.8 \\
$\mathrm{~T}-\mathrm{R}+$ & 5.9 & 10.3 & 18.4 & 0 & 5.7 \\
$\mathrm{~T}-\mathrm{R}-$ & 88.2 & 41.4 & 21 & 0 & 20 \\
\hline
\end{tabular}

$T$ tumor, $R$ resection margin, + presence of gene methylation, - lack of gene methylation

Recently, it has been reported that both DACT1 and DACT2 are methylated in oral squamous cell carcinoma [41]. CXXC4 encodes Idax protein which also antagonizes Wnt signaling by interacting with Disheveled. Its epigenetic downregulation led to the activation of Wnt signaling and was associated with poor outcome in gastric cancer patients [42]. FBXW11 encodes one of the components of the complex responsible for the ubiquitylation of $\beta$-catenin leading to its subsequent degradation, and to our knowledge, the methylation of this gene has not been studied in cancer so far, but the promoter region of this gene contains a $\mathrm{CpG}$ island which possibly may become methylated. In our current study, the methylation of
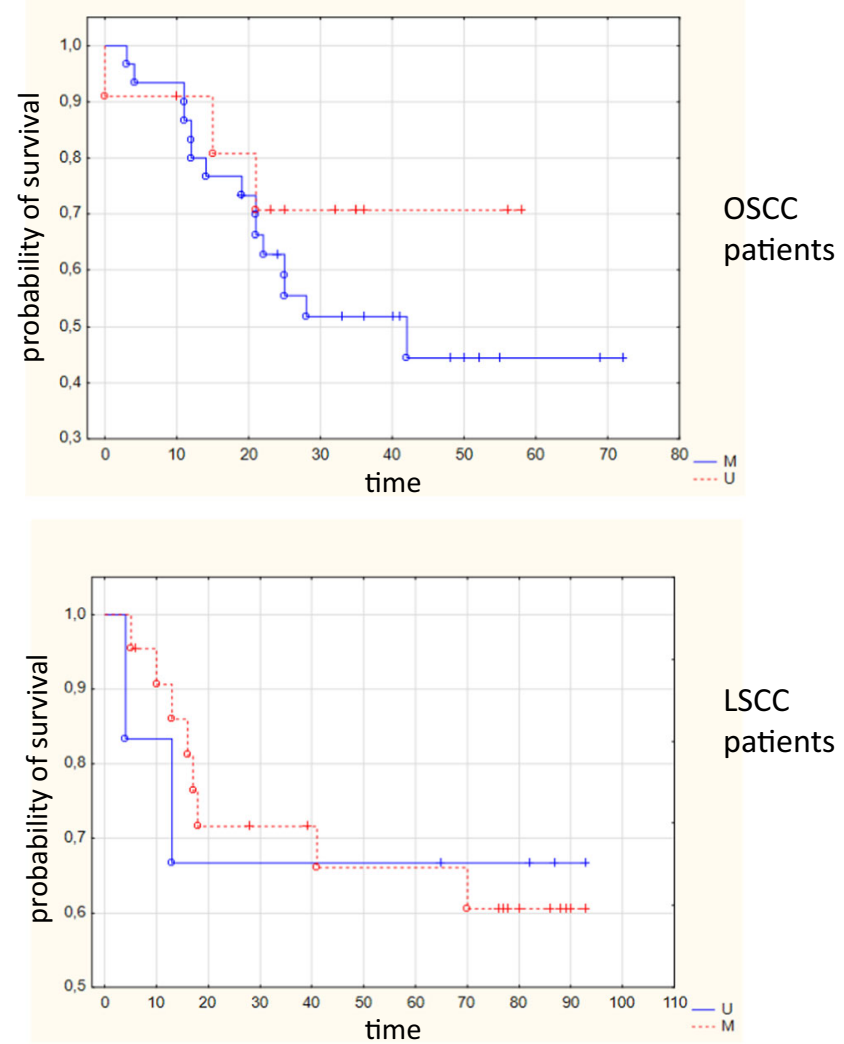

Fig. 4 Overall survival estimated by ZIC4 methylation detected in tumors of oral (OSCC) and laryngeal (LSCC) cancer patients. $M$ patients showing ZIC4 methylation; $U$ patients showing lack of ZIC4 methylation
HDPR 1 was marginal in the HNSCC cell lines; thus, it was not further investigated in the group of HNSCC patients. Similarly, we did not detect the methylation of the promoter region of FBXW11 in any of the tested HNSCC cell lines and thus did not investigate it further. On the other hand, we have observed that DACT2 is frequently methylated in both the cells lines and head and neck carcinomas while $C X X C 4$ is methylated to a lesser extent. Moreover, their methylation is not observed in normal epithelial cells derived from healthy subjects. However, the methylation of DACT2 or CXXC4 did not significantly correlate with the clinicopathological features of the patients.

Few studies investigated the epigenetic regulation of Shh signaling in head and neck carcinomas; thus, we aimed to assess whether known negative regulators of this pathway (HHIP, PTCH1, SUFU, ZIC1, ZIC4) undergo methylation in HNSCC. HHIP inhibits Shh signaling by sequestering $\mathrm{Hh}$ ligands which then cannot activate the pathway, and its epigenetically mediated downregulation was observed in gastrointestinal, hepatocellular, and pancreatic tumors [43-46]. PTCH1 blocks pathway activity in non-stimulated cells, and its loss due to methylation was observed in breast and gastric cancers and colorectal precancerous lesions [35, 46-48]. SUFU blocks the pathway by sequestering Gli transcription factors in the cytoplasm, and to our knowledge, its methylation has not been studied in cancer so far. ZIC1 and ZIC4 antagonize the transcriptional activity of Gli. Previous studies have shown that ZICl is frequently methylated in colorectal, hepatocellular, and gastric cancers [49-51] while the methylation of ZIC4 was observed in bladder cancer [52]. In our study, we have found lack of methylation of PTCH1 or SUFU and frequent methylation of HHIP, ZIC1, and ZIC4 in HNSCC. The observed lack of methylation of PTCH1 is in contrast to a recent finding where restriction analysis of promoter methylation showed that this gene is methylated in many dysplastic lesions and nearly half of HNSCC cases [53]. Methodological differences may be one possible source of this discrepancy. Another study reported that ZIC4 is methylated in a quarter of HNSCC cases [54]. To our knowledge, the methylation of HHIP has not been studied in HNSCC; however, it was reported that the expression of the encoded protein is lost in the majority of oral squamous cell carcinomas [55]. Thus, our observation that HHIP undergoes methylation may partly explain the mechanism of this loss in head and neck cancers. Importantly, ZIC4 methylation in tumors significantly correlated with lymph node invasion implicating that it might be considered a prognostic biomarker. Assuming that ZIC4 methylation leads to the upregulation of Gli1 signaling, it may be hypothesized that it would contribute to the induction of epithelial-to-mesenchymal transition what subsequently results in increased cell motility and invasion. Indeed, the enhancement in Shh-Gli1 signaling induced migration of pancreatic cancer cells [56, 57]. 
Epigenetic studies using DNA methylation-based markers frequently indicated that the use of a panel of genes has stronger diagnostic significance in comparison to single gene testing. In this regard, the panel consisting of $C X X C 4, D A C T 2$, $H H I P, Z I C 1$, and ZIC4 is a promising starting point for the development of a prognostic epimarker panel based on the finding that the MI value in tumor samples moderately correlated with the overall time of survival in the subgroup of 18 OSCC patients who died of the disease. Interestingly, the observed MI value in the surgical margin was higher in the case of OSCC patients who developed second primary tumors. Although this should be interpreted with great caution due to a low number of patients who developed second primary tumor during follow-up, this would be in agreement with the field carcinogenesis model which assumes that a diversity of molecular changes is detectable in a broad field of affected mucosa what may predispose cells to further neoplastic transformation $[58,59]$. In line with this model, epigenetic changes were observed not only in tumor sections but also in macroscopically normal surgical margin. The presence of epigenetic aberrations in surgical margin and distant mucosa in HNSCC is well documented $[16,60,61]$. These changes may constitute both part of the field of preneoplastic molecular alterations and be related to the presence of single neoplastic cells which are usually not detected under standard histopathological examination [61].

In summary, we report that CXXC4, DACT2, HHIP, ZIC1, and ZIC4 are methylated in head and neck squamous cell carcinomas. These findings corroborate that the activation of Wnt signaling in HNSCC is related to epigenetic silencing of the negative regulators of this pathway. Moreover, the results of our study indicate that the same mechanism of activation may operate in the case of Shh signaling. In this regard, functional studies should follow to investigate whether epigenetic modulators may inhibit Wnt or Shh signaling due to the reactivation of expression of pathway antagonists. Additionally, we conclude that the methylation of ZIC4 may be considered a new prognostic marker in HNSCC. Further investigations should determine the detailed diagnostic significance of methylation of ZIC4, HHIP, and DACT2 in head and neck carcinomas.

\section{Compliance with ethical standards}

Conflict of interest The authors declare that they have no conflict of interest.

Funding The work was supported by the Department of Pharmaceutical Biochemistry and the Faculty of Pharmacy, Poznan University of Medical Sciences in Poznań, Poland.

Ethical approval All procedures performed in studies involving human participants were in accordance with the ethical standards of the institutional and/or national research committee and with the 1964 Helsinki Declaration and its later amendments or comparable ethical standards.
Informed consent For this type of study, formal consent is not required.

Open Access This article is distributed under the terms of the Creative Commons Attribution 4.0 International License (http:// creativecommons.org/licenses/by/4.0/), which permits unrestricted use, distribution, and reproduction in any medium, provided you give appropriate credit to the original author(s) and the source, provide a link to the Creative Commons license, and indicate if changes were made.

\section{References}

1. GLOBOCAN 2012 v1.0, Cancer incidence and mortality worldwide: IARC CancerBase No. 11 [Internet]. [database on the Internet]. International Agency for Research on Cancer. 2013. Available from: http://globocan.iarc.fr. Accessed: 19.09.2015

2. Cancer in Poland in 2012 [database on the Internet]. Polish Registry of Cancer. 2014. Available from: http://onkologia.org.pl/wpcontent/uploads/Rok2012.pdf. Accessed: 18.09.2015

3. Leemans CR, Braakhuis BJ, Brakenhoff RH (2011) The molecular biology of head and neck cancer. Nature reviews. Cancer 11(1):922. doi:10.1038/nrc2982

4. Molinolo AA, Amornphimoltham P, Squarize CH, Castilho RM, Patel V, Gutkind JS (2009) Dysregulated molecular networks in head and neck carcinogenesis. Oral Oncol 45(45):324-334. doi:10.1016/j.oraloncology.2008.07.011

5. Rothenberg SM, Ellisen LW (2012) The molecular pathogenesis of head and neck squamous cell carcinoma. J Clin Investig 122(6): 1951-1957. doi:10.1172/jci59889

6. Saito-Diaz K, Chen TW, Wang X, et al. (2013) The way Wnt works: components and mechanism. Growth Factors 31(1):1-31. doi:10.3109/08977194.2012.752737

7. Alvarado CG, Maruyama S, Cheng J, et al. (2011) Nuclear translocation of beta-catenin synchronized with loss of E-cadherin in oral epithelial dysplasia with a characteristic two-phase appearance. Histopathology 59(2):283-291. doi: $10.1111 / \mathrm{j} .1365$ 2559.2011.03929.x

8. Ishida K, Ito S, Wada N, et al. (2007) Nuclear localization of betacatenin involved in precancerous change in oral leukoplakia. Mol Cancer 6:62. doi:10.1186/1476-4598-6-62

9. Iwai S, Yonekawa A, Harada C, Hamada M, Katagiri W, Nakazawa M, Yura Y (2010) Involvement of the Wnt- $\beta$-catenin pathway in invasion and migration of oral squamous carcinoma cells. Int $\mathrm{J}$ Oncol 37(5):1095-1103. doi:10.3892/ijo_00000761

10. Lee SH, Koo BS, Kim JM, et al. (2014) Wnt/beta-catenin signalling maintains self-renewal and tumourigenicity of head and neck squamous cell carcinoma stem-like cells by activating Oct4. J Pathol 234(1):99-107. doi:10.1002/path.4383

11. Ravindran G, Devaraj H (2012) Aberrant expression of beta-catenin and its association with DeltaNp63, Notch-1, and clinicopathological factors in oral squamous cell carcinoma. Clin Oral Investig 16(4):1275-1288. doi:10.1007/s00784-011-0605-0

12. Cancer Genome Atlas Network (2015) Comprehensive genomic characterization of head and neck squamous cell carcinomas. Nature 517(7536):576-582. doi:10.1038/nature14129

13. Lea IA, Jackson MA, Li X, Bailey S, Peddada SD, Dunnick JK (2007) Genetic pathways and mutation profiles of human cancers: site- and exposure-specific patterns. Carcinogenesis 28(9):18511858. doi:10.1093/carcin/bgm176

14. Pickering CR, Zhang J, Yoo SY, et al. (2013) Integrative genomic characterization of oral squamous cell carcinoma identifies frequent 
somatic drivers. Cancer Discov 3(7):770-781. doi:10.1158/21598290.CD-12-0537

15. Sogabe Y, Suzuki H, Toyota M, et al. (2008) Epigenetic inactivation of SFRP genes in oral squamous cell carcinoma. Int J Oncol 32(6): 1253-1261

16. Paluszczak J, Hemmerling D, Kostrzewska-Poczekaj M, et al. (2014) Frequent hypermethylation of WNT pathway genes in laryngeal squamous cell carcinomas. J Oral Pathol Med. doi:10.1111 /jop. 12178

17. Paluszczak J, Sarbak J, Kostrzewska-Poczekaj M, et al. (2015) The negative regulators of Wnt pathway-DACH1, DKK1, and WIF1 are methylated in oral and oropharyngeal cancer and WIF1 methylation predicts shorter survival. Tumour Biol 36(4):2855-2861. doi:10.1007/s13277-014-2913-x

18. Pannone G, Bufo P, Santoro A, Franco R, et al. (2010) WNT pathway in oral cancer: epigenetic inactivation of WNT-inhibitors. Oncol Rep 24:1035-1041. doi:10.3892/or_00000952

19. Duan Y, Fan M (2011) Lentivirus-mediated gene silencing of betacatenin inhibits growth of human tongue cancer cells. J Oral Pathol Med 40(8):643-650. doi:10.1111/j.1600-0714.2011.01007.x

20. McMillan R, Matsui W (2012) Molecular pathways: the hedgehog signaling pathway in cancer. Clin Cancer Res 18(18):4883-4888. doi:10.1158/1078-0432.CCR-11-2509

21. Cavicchioli Buim ME, Gurgel CA, Goncalves Ramos EA, Lourenco SV, Soares FA (2011) Activation of sonic hedgehog signaling in oral squamous cell carcinomas: a preliminary study. Hum Pathol 42(10):1484-1490. doi:10.1016/j.humpath.2010.12.015

22. Dimitrova K, Stoehr M, Dehghani F, et al. (2013) Overexpression of the hedgehog signalling pathway in head and neck squamous cell carcinoma. Onkologie 36(5):279-286. doi:10.1159/000350322

23. Leovic D, Sabol M, Ozretic P, et al. (2012) Hh-Gli signaling pathway activity in oral and oropharyngeal squamous cell carcinoma. Head \& neck. 34(1):104-112. doi:10.1002/hed.21696

24. Schneider S, Thurnher D, Kloimstein P, et al. (2011) Expression of the sonic hedgehog pathway in squamous cell carcinoma of the skin and the mucosa of the head and neck. Head \& neck. 33(2):244-250. doi:10.1002/hed.21437

25. Wang YF, Chang CJ, Lin CP, et al. (2012) Expression of hedgehog signaling molecules as a prognostic indicator of oral squamous cell carcinoma. Head \& neck 34(11):1556-1561. doi:10.1002 /hed.21958

26. Yan M, Wang L, Zuo H, et al. (2011) HH/GLI signalling as a new therapeutic target for patients with oral squamous cell carcinoma. Oral Oncol 47(6):504-509. doi:10.1016/j.oraloncology.2011.03.027

27. Mozet C, Stoehr M, Dimitrova K, Dietz A, Wichmann G (2013) Hedgehog targeting by cyclopamine suppresses head and neck squamous cell carcinoma and enhances chemotherapeutic effects. Anticancer Res 33(6):2415-2424

28. Fertig EJ, Markovic A, Danilova LV, et al. (2013) Preferential activation of the hedgehog pathway by epigenetic modulations in HPV negative HNSCC identified with meta-pathway analysis. PLoS One 8(11):e78127. doi:10.1371/journal.pone.0078127

29. Grenman R, Pekkola-Heino K, Joensuu H, Aitasalo K, Klemi P, Lakkala T (1992) UT-MUC-1, a new mucoepidermoid carcinoma cell line, and its radiosensitivity. Archives of otolaryngology - head \& neck surgery 118(5):542-547

30. Herman JG, Graff JR, Myohanen S, Nelkin BD, Baylin SB (1996) Methylation-specific PCR: a novel PCR assay for methylation status of CpG islands. Proc Natl Acad Sci U S A 93(18):9821-9826

31. Li LC, Dahiya R (2002) MethPrimer: designing primers for methylation PCRs. Bioinformatics 18(11):1427-1431

32. Jia Y, Yang Y, Brock MV, Zhan Q, Herman JG, Guo M (2013) Epigenetic regulation of DACT2, a key component of the Wnt signalling pathway in human lung cancer. J Pathol 230(2):194204. doi: $10.1002 /$ path. 4073
33. Yau TO, Chan CY, Chan KL, et al. (2005) HDPR1, a novel inhibitor of the WNT/beta-catenin signaling, is frequently downregulated in hepatocellular carcinoma: involvement of methylation-mediated gene silencing. Oncogene 24(9):1607-1614. doi:10.1038/sj. onc. 1208340

34. Eichenmuller M, Gruner I, Hagl B, et al. (2009) Blocking the hedgehog pathway inhibits hepatoblastoma growth. Hepatology 49(2):482-490. doi:10.1002/hep.22649

35. Peng L, Hu J, Li S, et al. (2013) Aberrant methylation of the PTCH1 gene promoter region in aberrant crypt foci. Int $\mathrm{j}$ cancer 132(2): E18-E25. doi:10.1002/ijc.27812

36. Yu Y, Yan W, Liu X, et al. (2014) DACT2 is frequently methylated in human gastric cancer and methylation of DACT2 activated Wnt signaling. Am J Cancer Res 4(6):710-724

37. Zhao Z, Herman JG, Brock MV, et al. (2014) Methylation of DACT2 promotes papillary thyroid cancer metastasis by activating Wnt signaling. PLoS One 9(11):e112336. doi:10.1371/journal. pone. 0112336

38. Yin X, Xiang T, Li L, et al. (2013) DACT1, an antagonist to Wnt/ beta-catenin signaling, suppresses tumor cell growth and is frequently silenced in breast cancer. Breast cancer res 15(2):R23. doi:10.1186/bcr3399

39. Yang ZQ, Zhao Y, Liu Y, et al. (2010) Downregulation of HDPR1 is associated with poor prognosis and affects expression levels of p120-catenin and beta-catenin in nonsmall cell lung cancer. Mol Carcinog 49(5):508-519. doi:10.1002/mc.20622

40. Deng J, Liang H, Zhang R, et al. (2014) Methylated CpG site count of dapper homolog 1 (DACT1) promoter prediction the poor survival of gastric cancer. Am J Cancer Res 4(5):518-527

41. Schussel JL, Kalinke LP, Sassi LM, et al. (2015) Expression and epigenetic regulation of DACT1 and DACT2 in oral squamous cell carcinoma. Cancer Biomark 15(1):11-17. doi:10.3233/cbm140436

42. Lu H, Sun J, Wang F, et al. (2013) Enhancer of zeste homolog 2 activates wnt signaling through downregulating CXXC finger protein 4. Cell Death Dis 4:e776. doi:10.1038/cddis.2013.293

43. Taniguchi H, Yamamoto H, Akutsu N, et al. (2007) Transcriptional silencing of hedgehog-interacting protein by $\mathrm{CpG}$ hypermethylation and chromatic structure in human gastrointestinal cancer. $\mathrm{J}$ Pathol 213(2):131-139. doi:10.1002/path.2216

44. Tada M, Kanai F, Tanaka Y, et al. (2008) Down-regulation of hedgehog-interacting protein through genetic and epigenetic alterations in human hepatocellular carcinoma. Clin Cancer Res 14(12): 3768-3776. doi:10.1158/1078-0432.ccr-07-1181

45. Martin ST, Sato N, Dhara S, et al. (2005) Aberrant methylation of the human hedgehog interacting protein (HHIP) gene in pancreatic neoplasms. Cancer Biol Ther 4(7):728-733

46. Song Y, Tian Y, Zuo Y, JC T, Feng YF, Qu CJ (2013) Altered expression of PTCH and HHIP in gastric cancer through their gene promoter methylation: novel targets for gastric cancer. Mol Med Rep 7(4):1159-1168. doi:10.3892/mmr.2013.1333

47. Zuo Y, Song Y (2013) Detection and analysis of the methylation status of PTCH1 gene involved in the hedgehog signaling pathway in a human gastric cancer cell line. Exp Ther Med 6(6):1365-1368. doi:10.3892/etm.2013.1334

48. Wolf I, Bose S, Desmond JC, et al. (2007) Unmasking of epigenetically silenced genes reveals DNA promoter methylation and reduced expression of PTCH in breast cancer. Breast Cancer Res Treat 105(2):139-155. doi:10.1007/s10549-006-9440-4

49. Gan L, Chen S, Zhong J, et al. (2011) ZIC1 is downregulated through promoter hypermethylation, and functions as a tumor suppressor gene in colorectal cancer. PLoS One 6(2):e16916. doi:10.1371/journal.pone.0016916

50. Wang YY, Jiang JX, Ma H, et al. (2014) Role of ZIC1 methylation in hepatocellular carcinoma and its clinical significance. Tumour Biol 35(8):7429-7433. doi:10.1007/s13277-014-1971-4 
51. Wang LJ, Jin HC, Wang X, et al. (2009) ZIC1 is downregulated through promoter hypermethylation in gastric cancer. Biochem Biophys Res Commun 379(4):959-963. doi:10.1016/j. bbrc.2008.12.180

52. Kandimalla R, van Tilborg AA, Kompier LC, et al. (2012) Genome-wide analysis of $\mathrm{CpG}$ island methylation in bladder cancer identified TBX2, TBX3, GATA2, and ZIC4 as pTa-specific prognostic markers. Eur Urol 61(6):1245-1256. doi:10.1016/j. eururo.2012.01.011

53. Ghosh A, Ghosh S, Maiti GP, et al. (2012) Association of FANCC and PTCH1 with the development of early dysplastic lesions of the head and neck. Ann Surg Oncol 19 Suppl 3:S528-S538. doi:10.1245/s10434-011-1991-x

54. Guerrero-Preston R, Michailidi C, Marchionni L, et al. (2014) Key tumor suppressor genes inactivated by "greater promoter" methylation and somatic mutations in head and neck cancer. Epigenetics 9(7). doi:10.4161/epi.29025

55. Snijders AM, Schmidt BL, Fridlyand J, et al. (2005) Rare amplicons implicate frequent deregulation of cell fate specification pathways in oral squamous cell carcinoma. Oncogene 24(26): 4232-4242. doi:10.1038/sj.onc.1208601

56. Xu X, Zhou Y, Xie C, et al. (2012) Genome-wide screening reveals an EMT molecular network mediated by sonic hedgehog-Gli1 signaling in pancreatic cancer cells. PLoS One 7(8):e43119. doi:10.1371/journal.pone.0043119

57. Xu X, Su B, Xie C, et al. (2014) Sonic hedgehog-Gli1 signaling pathway regulates the epithelial mesenchymal transition (EMT) by mediating a new target gene, S100 A4, in pancreatic cancer cells. PLoS One 9(7):e96441. doi:10.1371/journal.pone.0096441

58. Dotto GP (2014) Multifocal epithelial tumors and field cancerization: stroma as a primary determinant. J Clin Invest 124(4):1446-1453. doi:10.1172/JCI72589

59. Mohan M, Jagannathan N (2014) Oral field cancerization: an update on current concepts. Oncol Rev 8(1):244. doi:10.4081 /oncol.2014.244

60. Paluszczak J, Misiak P, Wierzbicka M, Wozniak A, BaerDubowska W (2011) Frequent hypermethylation of DAPK, RARbeta, MGMT, RASSF1A and FHIT in laryngeal squamous cell carcinomas and adjacent normal mucosa. Oral Oncol 47(2): 104-107. doi:10.1016/j.oraloncology.2010.11.006

61. Mielcarek-Kuchta D, Paluszczak J, Seget M, et al. (2014) Prognostic factors in oral and oropharyngeal cancer based on ultrastructural analysis and DNA methylation of the tumor and surgical margin. Tumour biol 35(8):7441-7449. doi:10.1007/s13277-0141958-1 